\title{
Graphene Oxides Coated Paper as a Substrate to Paper Spray Ionization Mass Spectrometry for Creatinine Determination in Urine Samples
}

\author{
Aline R. Fernandes, ${ }^{a}$ Ricardo A. Bernardo, ${ }^{a}$ Thays C. de Carvalho, ${ }^{a}$ Boniek G. Vaz ${ }^{a}$ and \\ Andréa R. Chaves ${ }^{\circledR} * a$ \\ ${ }^{a}$ Laboratório de Cromatografia e Espectrometria de Massas (LaCEM), Instituto de Química, \\ Universidade Federal de Goiás, 74690-900 Goiânia-GO, Brazil
}

\begin{abstract}
Paper spray ionization (PSI) is a promising analytical tool for direct analysis in mass spectrometry (MS). However, this technique usually uses chromatographic paper, which rarely accomplishes a stable MS signal and could vary with the sample matrix effect. In the present study, the application of graphene oxides (GO) was scrutinized as modifier paper substrate for PSI-MS methods. The developed substrate efficiency was evaluated towards creatinine determination in urine samples. The GO-PSI-MS developed method for creatinine in urine samples showed linearity in the range of 0.1 to $3.4 \mathrm{ppm}$ with $\mathrm{R}^{2}=0.9991$. The precision was evaluated and the values were between 1.1 to $6.8 \%$ and the accuracy above $96.8 \%$. The limit of quantification (LOQ) and limit of detection (LOD) were 0.05 and $0.17 \mathrm{ppm}$, respectively. The GO-PSI developed was compared to conventional chromatographic paper for PSI-MS methods, and the results showed that the modified paper with GO bolsters method linearity, precision, and LOQ values.
\end{abstract}

Keywords: paper spray ionization, graphene oxide, creatinine, urine, mass spectrometry

\section{Introduction}

Introduced in 2010 by Wang et al., ${ }^{1}$ paper spray ionization mass spectrometry (PSI-MS) is a new ambient mass spectrometry technique for qualitative and quantitative analysis of complex matrices, presented to be the simplest as possible compared to desorption electrospray (DESI) and direct analysis in real time (DART). ${ }^{1}$ Since then, a plethora of publication employing PSI technique has been explored for different applications, mainly to analyze directly samples of blood, urine, saliva, tissues, cell cultures, water and bacteria. ${ }^{2-12}$ Moreover, other elements, such as wick microporous polymers, ${ }^{13}$ wooden toothpicks, ${ }^{14}$ plant leaves (leaf spray), or other vegetable materials were also employed as both sample and substrate. ${ }^{15}$

The PSI-MS methods involve directly loading the sample onto a triangular paper, which is moistened with an organic solvent and placed in front of a mass spectrometer inlet. The spray of the charged microdroplets is formed by applicating a high voltage (usually ca. $1-5 \mathrm{kV}$ ) on the opposite side of the paper tip, and desolvation occurs without any sheath gas. ${ }^{16}$ The PSI-MS mechanism of ion formation is similar to electrospray ionization (ESI) process. Briefly, the strong

*e-mail: andrea_chaves@ufg.br electric field at the sharp tip of the paper results in the formation of an electrolytic spray in Taylor's cone shape, which consists of a plume of charged droplets. After the desolvation, the ions are evaporated to the gas phase.

Some parameters for PSI had been investigated by Cooks and co-workers, ${ }^{16}$ and had been previously demonstrated in the literature, such as paper geometry ${ }^{17}$ and onset voltage for spray generation efficiency. ${ }^{18}$ Despite this, MS signal stability is impaired due to the low conductivity of paper, desorption solvent evaporation on the paper results in the variance of the produced spray. ${ }^{16}$

Graphene oxide (GO) is a single-atom-thick and twodimensional carbon material produced by oxidation of graphite, containing oxygen functional groups, such as epoxides, phenol hydroxyls and carboxylic groups. ${ }^{19,20}$ The oxygenated framework of GO not only facilitates better conductivity and signal stability but also allows noncovalent interaction with diols, amine functional groups, and phenyls in biomolecules through electrostatic interaction, $\pi-\pi$ stacking, and hydrogen bonding to enable recognizing of biomolecules with detectable specificity. ${ }^{21,22}$ Recently, GO has attracted considerable attention due to its extraordinary electronic, optical, and thermal properties in comparison to other nanomaterials. ${ }^{23}$ Remarkable properties of GO, such as large surface area, good water dispersibility 
and biocompatibility, facile surface modification and low manufacturing cost, make it a promising material for biotechnology and biosensor application. ${ }^{24-30}$ The aforementioned attributes become $\mathrm{GO}$ a potential material to modify paper surface for PSI-MS application. Wei et al. ${ }^{29}$ described in 2018 a procedure to immobilize GO onto nylon membrane to analyze highly toxic disinfectants in liquid samples and fish meat. The authors reported an enhancement in selectivity and sensitivity for the MS quantification due to the thin layer of GO. To the best of our knowledge, this is the first report regarding the use of GO chemically immobilized onto the paper surface for PSI-MS methods.

Creatinine is an important biochemical parameter to correctly determine the urinary excretion rate of endogenous and exogenous compounds. ${ }^{31}$ Accurate creatinine determination is essential for diagnosis and treatment of renal diseases, thyroid malfunction and muscle disorders. ${ }^{32,33}$ The creatinine quantification in urine in clinical laboratories is routinely performed by the Jaffe method or by enzymatic methods, which may suffer from interference like bilirubin, proteins, ketones and glucose. Thus, it is essential to develop efficient, quick and more reliable interferencefree methods. ${ }^{34,35}$ Besides this, creatinine structure is a good molecule model for mass spectrometric method, due to their good ionization efficiency and well related fragmentation profile in MS/MS experiments.

In this study, GO was chemically immobilized onto a chromatographic paper surface and employed as a substrate for PSI-MS method for creatinine determination in urine samples. The developed GO-PSI-MS method was also evaluated to health check for creatinine levels in real urine samples.

\section{Experimental}

Materials

Creatinine $\left(\mathrm{C}_{4} \mathrm{H}_{7} \mathrm{~N}_{3} \mathrm{O}\right.$, purity $\left.\geq 98 \%\right)$, uric acid $\left(\mathrm{C}_{5} \mathrm{H}_{4} \mathrm{~N}_{4} \mathrm{O}_{3}\right.$, purity $\geq 99 \%$ ), graphite (purity $\geq 99.99 \%$ ), and potassium bromide (purity $\geq 99 \%$ ) were obtained from Sigma-Aldrich. Methanol (high-performance liquid chromatography (HPLC) grade, 99.9\%, Vetec Química Fina) was used to moisten the blotter for the ionization process. Formic acid (purity $\geq 98 \%$, Sigma-Aldrich) was used for the PSI(+)-MS measurements.

\section{Synthesis of graphene oxide}

GO was synthesized from natural graphite powder based on Hummer's protocol described by Gao et al. ${ }^{19}$ Briefly,
$\mathrm{KMnO}_{4}$ was slowly added into a mixture of graphite, $\mathrm{NaNO}_{3}$, and $\mathrm{H}_{2} \mathrm{SO}_{4}$ in an ice bath, then the mixture was transferred to a $35^{\circ} \mathrm{C}$ water bath and stirred for about $1 \mathrm{~h}$. After that, $100 \mathrm{~mL}$ water were added, and the suspension was stirred for $30 \mathrm{~min}$ at $90{ }^{\circ} \mathrm{C}$ to oxidize graphite. Next, water and $\mathrm{H}_{2} \mathrm{O}_{2}(30 \mathrm{wt} . \%)$ solution were added to terminate the reaction. Then the product was filtered and washed with $1 \mathrm{~mol} \mathrm{~L}^{-1} \mathrm{HCl}$ and water two times, respectively. At last, the obtained brown solid was dried at $60^{\circ} \mathrm{C}$ for $24 \mathrm{~h}$.

\section{Preparation of GO-modified paper}

Paper triangles were cut from chromatography paper using a CUTOK DC craft cutting plotter (Hefei CNC Equipment Co.). The paper triangles had an angle of $38^{\circ}$ and an area of ca. $60 \mathrm{~mm}^{2}$ (base width $=9 \mathrm{~mm}$, height $=13.2 \mathrm{~mm}$ ). The paper triangles were immersed in a suspension of graphene oxide in $5 \mathrm{wt} . \%$ methanol under constant magnetic stirring and then a $3 \mathrm{wt} . \%$ aminopropyltrietoxysiloxane (APTS) was added. The calculated mass of GO deposited in the paper surface was about $9.15 \mathrm{mg}$. The wet triangular paper was let to dry overnight (24 h). Afterward, the papers were washed with $1 \mathrm{~mL}$ of methanol and dried at room temperature.

\section{GO-paper characterization}

To evaluate the morphological properties of the developed modified paper a scanning electron microscope (SEM) (Jeol JSM-6610, with energy-dispersive X-ray spectroscopy (EDS)) was used. The paper samples were cut in square shape $(0.5 \times 0.5 \mathrm{~cm})$ and directly analyzed in the equipment without any sample preparation.

Fourier transform infrared spectroscopy (FTIR) analysis of the developed graphene oxides and graphite samples was performed in a PerkinElmer Spectrum 400 FT-IR/FT-FIR Spectrometer, using a pellet of graphene oxide or graphite sample in $\operatorname{KBr}(1 \mathrm{wt} . \%)$ mixture.

\section{Synthetic urine}

For the optimization and analytical validation assays, synthetic urine was used. The synthetic urine was prepared by dissolving $3.333 \mathrm{~g} \mathrm{~L}^{-1}$ of urea $\left(\mathrm{CH}_{4} \mathrm{~N}_{2} \mathrm{O}\right), 0.050 \mathrm{~g} \mathrm{~L}^{-1}$ of uric acid, $0.177 \mathrm{~g} \mathrm{~L}^{-1}$ of creatinine, $1.000 \mathrm{~g} \mathrm{~L}^{-1}$ of chloride $\left(\mathrm{Cl}^{-}\right), 1.000 \mathrm{~g} \mathrm{~L}^{-1}$ of potassium $\left(\mathrm{K}^{+}\right), 0.025 \mathrm{~g} \mathrm{~L}^{-1}$ of phosphate $\left(\mathrm{PO}_{4}^{3-}\right), 0.300 \mathrm{~g} \mathrm{~L}^{-1}$ of sulfate $\left(\mathrm{SO}_{4}^{2-}\right), 0.025 \mathrm{~g} \mathrm{~L}^{-1}$ of calcium $\left(\mathrm{Ca}^{2+}\right), 0.0167 \mathrm{~g} \mathrm{~L}^{-1}$ of magnesium $\left(\mathrm{Mg}^{2+}\right), 0.167 \mathrm{~g} \mathrm{~L}^{-1}$ of sodium $\left(\mathrm{Na}^{+}\right), 0.025 \mathrm{~g} \mathrm{~L}^{-1}$ of ammonium $\left(\mathrm{NH}_{4}^{+}\right)$, and $0.167 \mathrm{~g} \mathrm{~L}^{-1}$ of carbonates $\left(\mathrm{CO}_{3}{ }^{2-}\right)$ in $1 \mathrm{~L}$ of ultra-purified water. ${ }^{36}$ These salts were obtained from Dinâmica. 


\section{Paper spray}

The procedure for preparation and analysis with GO-paper spray is represented in Figure 1.

Paper spray was performed using a 3D ion trap mass spectrometer (LCQ Fleet ${ }^{\mathrm{TM}}$, Thermo Scientific) with the following instrumental parameters. Spray voltage, capillary voltage, and tube lens offset were set at 0 , the capillary temperature at $275^{\circ} \mathrm{C}$, and positive ion mode was employed. The paper triangle was held about 5-10 $\mathrm{mm}$ from the MS inlet. After, with the aid of a micropipette, $10 \mu \mathrm{L}$ of urine sample were directly spiked on the GO-paper surface, and then, $10 \mu \mathrm{L}$ acid solvent ( $0.1 \%$ formic acid in methanol) were added to enhance creatinine ionization. ${ }^{37}$ After that, a high voltage $(3.0 \mathrm{kV})$ was applied to the paper to generate an electrospray, and mass spectra were recorded. All assays were performed in triplicate.

\section{Quantitative PSI-MS analyses}

Samples were prepared using ten standard-spiked synthetic urine samples with concentrations in the range from 0.1 to $3.4 \mathrm{ppm}$ of creatinine. For the analytical curves, the intensity of $\mathrm{m} / \mathrm{z}, 88$ creatinine fragment integrated in $30 \mathrm{~s}$ of spray was used both for GO-modified paper and chromatographic paper. The limit of detection (LOD) was defined as the minimum detectable concentration of spiked samples with a signal/noise ratio greater than three. Similarly, the limit of quantification (LOQ) was defined for a signal-to-noise $(\mathrm{S} / \mathrm{N})$ ratio above ten. Precision, accuracy and absolute recovery were evaluated in three concentration levels $(0.1,1.4$ and $3.4 \mathrm{ppm})$ performed in replicates $(n=5)$. Accuracy $($ Acc $\%)$ is a measure of how near the experimentally determined concentration is to the theoretical concentration. Its values were calculated by comparing the concentrations of analytes added to the synthetic urine samples and the determined concentration by the analytical curve, as described in equation 1 . The absolute recovery (Rec\%) measures the efficiency of an extraction/desorption procedure in an analytical method within a limit of variation. Its values were calculated comparing the peak intensity of the most abundant fragment ion of extracted creatinine from the synthetic urine with those at the same concentration in standard solutions of the analyte, as described in equation 2 .

$$
\begin{aligned}
& \operatorname{Acc} \%=\left[\frac{\mathrm{CDE}-\mathrm{TC}}{\mathrm{TC}}\right] \times 100 \\
& \operatorname{Rec} \%=\left[\frac{\mathrm{CDE}}{\mathrm{TC}}\right] \times 100
\end{aligned}
$$

where $\mathrm{CDE}$ is the concentration determined experimentally, and TC is the theoretical concentration.

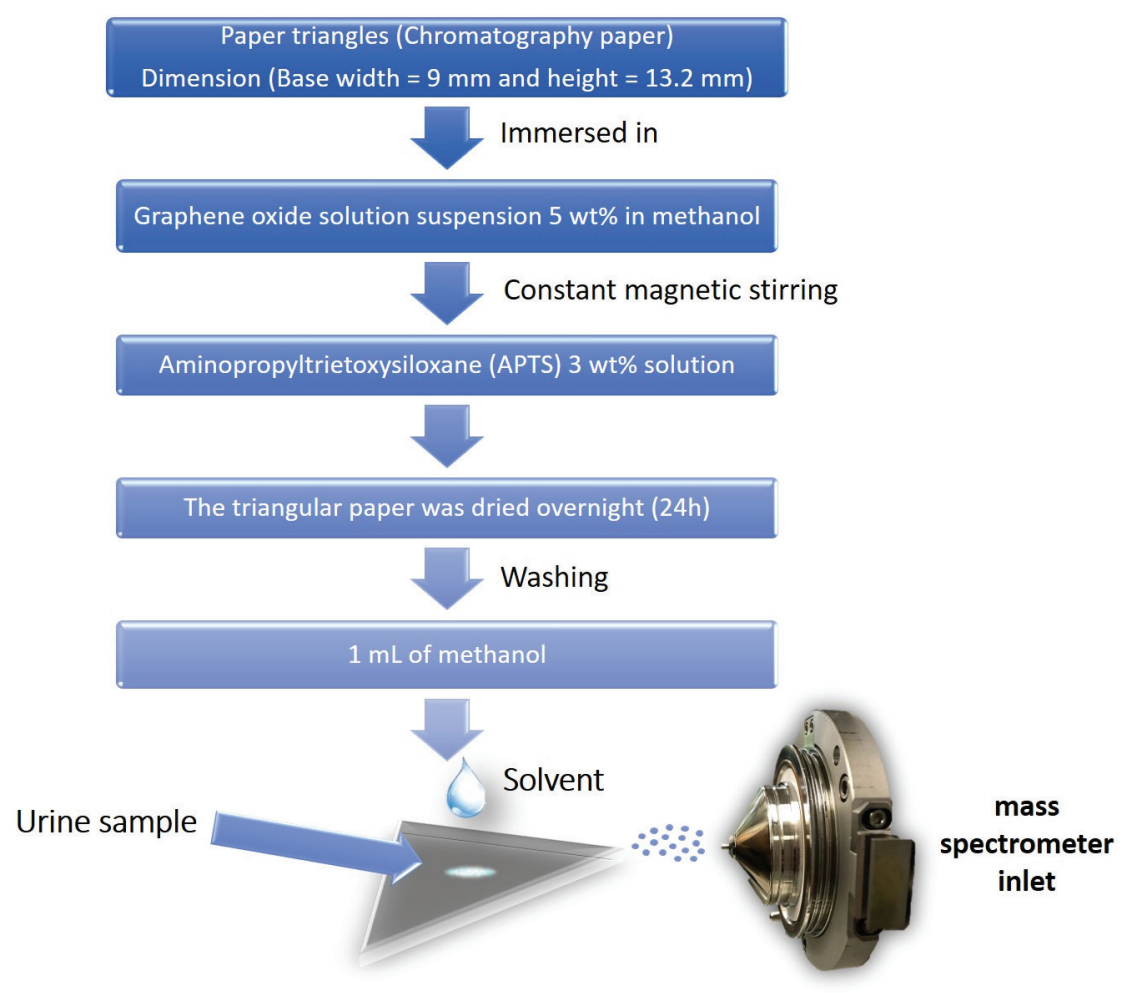

Figure 1. Schematic representation of GO synthesis and GO-PSI-MS arrangement. 
Urine samples

Urine samples were collected from healthy volunteers and kept for four days at $2-8{ }^{\circ} \mathrm{C}$ and one freezing drowning. The samples were collected following the ethics principles and had been approved by the Universidade Federal de Goiás' ethical committee (Comitê de Ética em Pesquisa (CEP) 056/13).

\section{Results and Discussion}

Biological fluids, like urine, present many endogenous compounds and salts, which could results in several problems in ESI techniques.

Chemical modification onto paper surface could improve selective and desorption/ionization of PSI-MS methods, as shown in the literature. ${ }^{38,39}$ Thereby, graphene oxides could enhance the conductivity of paper substrate resulting in better MS signal.

\section{Characterization of graphene oxide}

The synthesized graphene oxides were characterized by FTIR analysis. Figures $2 \mathrm{a}$ and $2 \mathrm{~b}$ show the FTIR spectrum of graphite and GO, respectively. Comparing to the graphite FTIR spectrum, the GO presents the strong characteristic peak at $3318 \mathrm{~cm}^{-1}$ for $\mathrm{O}-\mathrm{H}(v \mathrm{O}-\mathrm{H})$, $1724 \mathrm{~cm}^{-1}$ for $-\mathrm{C}=\mathrm{O}(\vee \mathrm{C}=\mathrm{O}), \mathrm{C}-\mathrm{O}-\mathrm{C}(v \mathrm{C}-\mathrm{O}-\mathrm{C})$ at $1350 \mathrm{~cm}^{-1}$ and $-\mathrm{C}-\mathrm{O}(\vee \mathrm{C}-\mathrm{O})$ at $1100 \mathrm{~cm}^{-1}$, indicating that $\mathrm{GO}$ possessed rich oxygen-containing groups including hydroxyl and carboxyl groups (Figure 2b), while graphite spectrum (Figure 2a) presents only the peaks at $1612 \mathrm{~cm}^{-1}$ for aromatic $\mathrm{C}=\mathrm{C}(\vee \mathrm{C}=\mathrm{C})$ and $3318 \mathrm{~cm}^{-1}$ for $-\mathrm{O}-\mathrm{H}(v \mathrm{O}-\mathrm{H})$. The peak at $1612 \mathrm{~cm}^{-1}$ for aromatic $\mathrm{C}=\mathrm{C}$ $(\vee \mathrm{C}=\mathrm{C}$ ) is due to the skeletal vibrations of non-oxidized graphitic domains. The data obtained were very similar to those presented by Chen et al. ${ }^{40}$ that developed a cheap, massively scalable, fast and easy method for the preparation of graphene oxide and reduced nanoplatelets of graphene oxide. The basic strategy was the preparation of graphite oxide from graphite through reaction with benzoyl peroxide (BPO), complete exfoliation of GO on graphene oxide sheets, followed by in situ reductions of reduced graphene oxide nanoplatelets.

A triangular shaped cellulosic paper was modified with GO synthesized as mentioned in the "Preparation of GO-modified paper" sub-section. The modified GO paper was evaluated by SEM.

Figure 3 shows the SEM image of the GO-modified paper. It is possible to note in Figure 3 the presence of small agglomerates of particles immobilized into
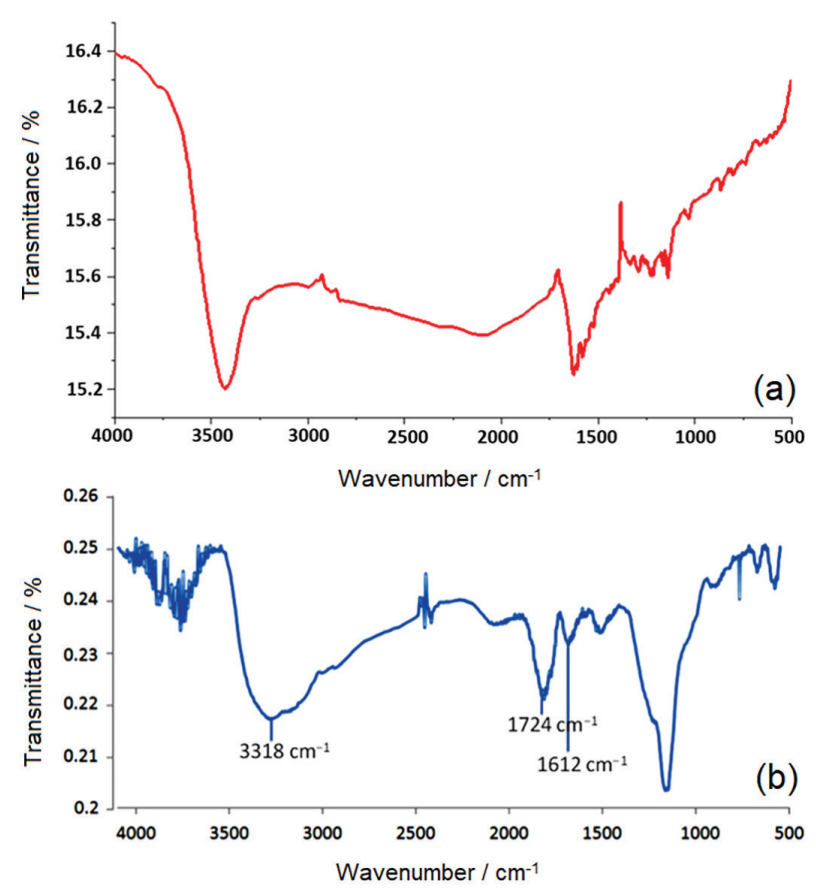

Figure 2. FTIR spectrum of (a) graphite and (b) graphene oxides samples.

the pores of the chromatographic paper present in its entire structure, which are not observed in the native chromatographic paper.

\section{Paper spray properties of GO-modified paper}

The effects of spray voltage on GO-PSI-MS in positive ion mode were evaluated. Cooks and co-workers ${ }^{18}$ reported the use of $4.5 \mathrm{kV}$ to promote the spray formation through PSI-MS. Due to the electronic properties of GO, an adequate efficiency and precision were obtained using $3.0 \mathrm{kV}$ as spray potential. So, $3.0 \mathrm{kV}$ was used because satisfactory ionization efficiency was observed.

In order to demonstrate the applicability of GO-modified paper on PSI-MS method, creatinine was analyzed in urine samples. Creatinine is a good model molecule; it presents a well-related MS profile and its structure seems to be interesting for other similar drugs and protein studies. The comparison between the mass spectra of GO-modified paper and chromatographic paper in synthetic urine samples demonstrated that the first one increased the stability of spray (Figure 4).

PSI ionization is ESI-based, this technique is usually incompatible with traditional buffers and nonvolatile salts, ${ }^{41-45}$ with even their small amounts sometimes affecting electrospray stability and significantly suppressing analyte signals, resulting in poor $\mathrm{S} / \mathrm{N}$ ratios (ionization suppression). Therefore, the salt-induced ionization suppression in PSI-MS cannot be ignored. 


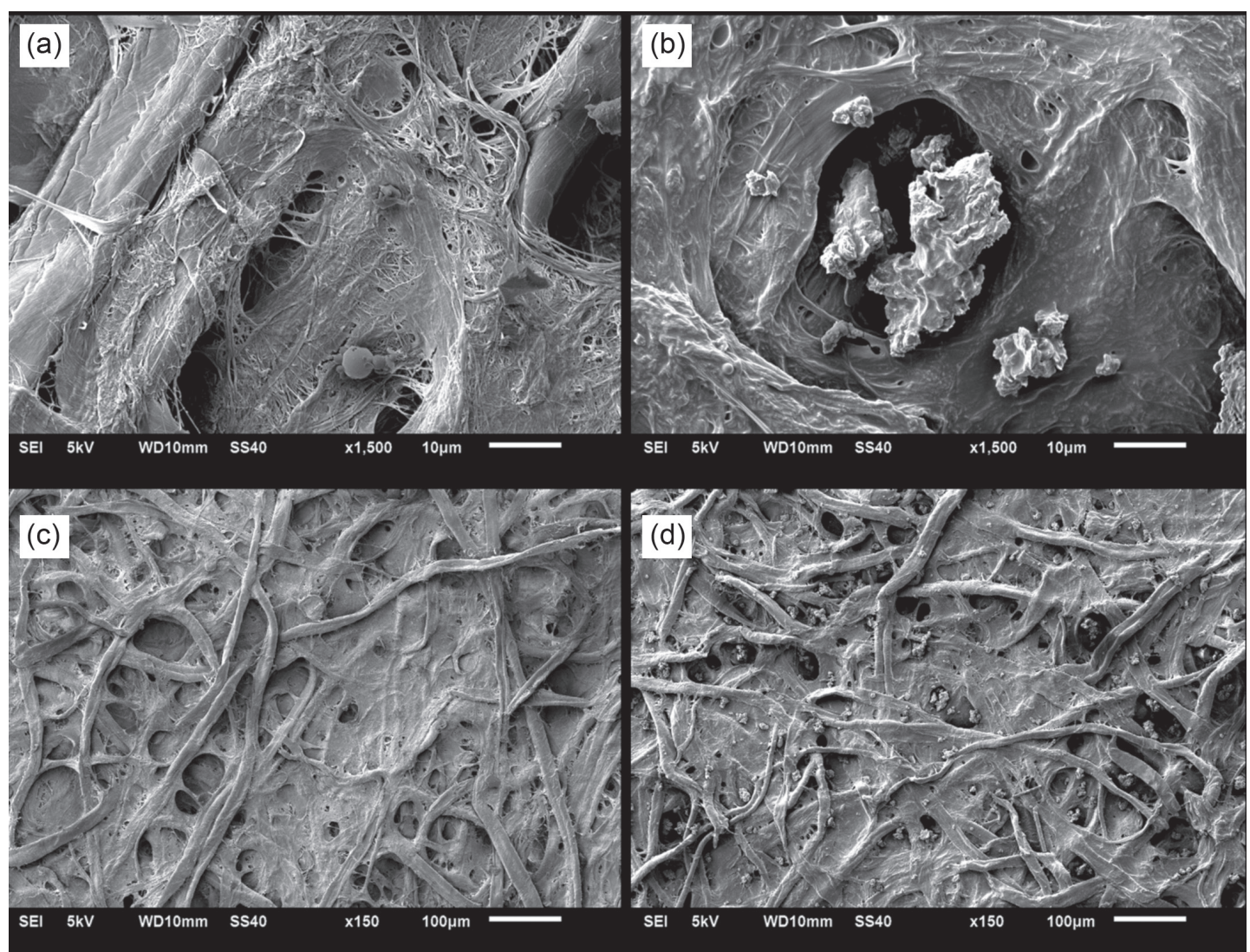

Figure 3. SEM images of chromatographic paper magnified at (a) 1500x and (c) 150x; and GO-modified paper magnified at (b) $1500 \times$ and (d) $150 \times$.
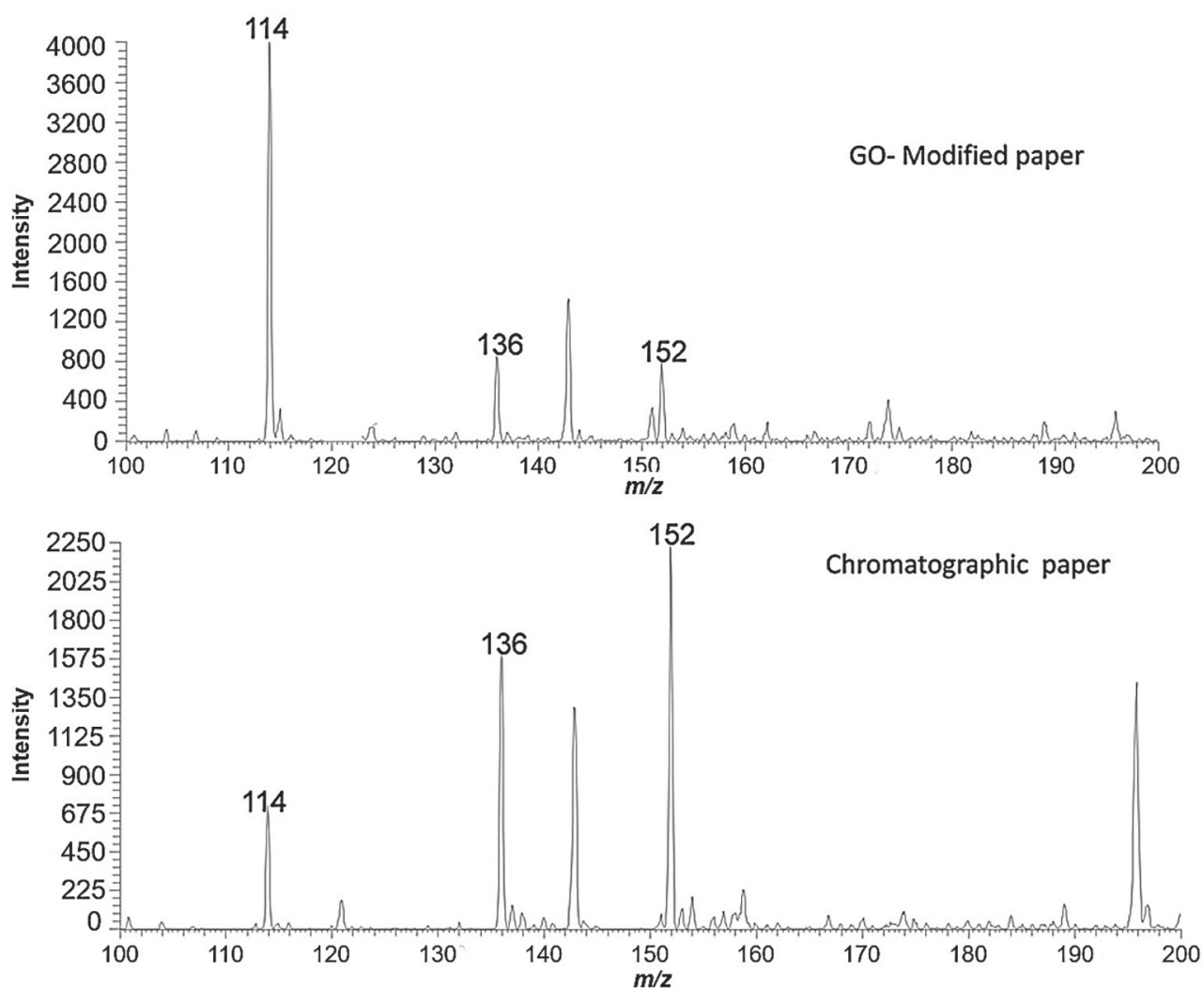

Figure 4. PSI(+)-MS of creatinine for GO-modified paper (top) and chromatographic paper (bottom). $m / z 114=[\mathrm{M}+\mathrm{H}]^{+}, \mathrm{m} / z 136=[\mathrm{M}+\mathrm{Na}]^{+}$; $m / z 152=[\mathrm{M}+\mathrm{K}]^{+}$. 
Avoiding the salt-induced ionization suppression is very important to achieve highly sensitive PSI-MS quantitative analysis. Although a number of desalting methods have been established for HPLC/ESI-MS, such as online electrodialysis, offline gel filtration, solid-phase extraction, microdialysis, and multistage electrolysis, they are difficult to implement and are seldom used in PSI-MS. Thus, developing new desalting strategies is important for PSI-MS.

Urine is a biological matrix composed largely of ions $\left(\mathrm{Cl}^{-}, \mathrm{K}^{+}, \mathrm{PO}_{4}{ }^{3-}, \mathrm{SO}_{4}{ }^{2-}, \mathrm{Ca}^{2+}, \mathrm{Mg}^{2+}, \mathrm{Na}^{+}, \mathrm{NH}_{4}^{+}\right.$, $\left.\mathrm{CO}_{3}{ }^{2-}\right){ }^{40}$ In GO-PSI-MS creatinine analyses, protonated creatinine ion presents a higher intensity compared to its sodium and potassium adducts ion signals, whereas using chromatographic paper protonated creatinine signal intensity is less than half, as shown in Figure 4. The real samples analysis showed the same spectrum profile. The $\mathrm{PSI}(+)$ mass spectrum of creatinine in real samples is shown in Figure 5. Note that it was detected as protonated molecule $[\mathrm{M}+\mathrm{H}]^{+}$of $m / z, 114$ and as sodium and potassium adducts, $[\mathrm{M}+\mathrm{Na}]^{+}$of $m / z, 136$ and $[\mathrm{M}+\mathrm{K}]^{+}$of $m / z, 152$, respectively.

Using chromatographic paper the detection ability of the method is reduced due to a decrease in the analyte signal, as a result higher LOD could be observed. The ratio of ions, precision, linearity, and quantification may be affected due to the variability of the matrix effect between samples. All of these factors can lead to a false negative in positive samples since the method was developed for creatinine and not for adducts. ${ }^{44}$

The chemical structure of the analyte was confirmed by its fragment ions in collision induced dissociation (CID) experiments, as previously described in the literature, ${ }^{46}$ and PSI(+)-MS/MS dissociation. The MS/MS spectrum is shown in Figure S1 (Supplementary Information (SI) section); creatinine $(\mathrm{m} / \mathrm{z}, 114)$ is characterized by the loss of $\mathrm{CO}$ leading to the formation of the $\left[\mathrm{C}_{3} \mathrm{H}_{8} \mathrm{~N}_{3}\right]^{+}$ion with $\mathrm{m} / \mathrm{z} 86$.

Additionally, modifying the paper with a graphene oxide film increases MS spray time. The spray time using chromatographic paper showed a decrease in $1.2 \mathrm{~min}$ while the spray using GO-modified paper showed stability until $2.0 \mathrm{~min}$. Besides this, the efficiency decreases abruptly for the chromatographic paper; this decrease is slower for GO-modified paper even after $2.0 \mathrm{~min}$. Graphene oxide has several functional groups, such as epoxy, hydroxyl, and carbonyl, in its basal planes and edges. These groups exhibit hydrophilic properties, polar groups, retaining longer the solution applied to the paper, making elution to the mass spectrometer slower. ${ }^{24-31}$ Figure S2 (SI section) shows the total ion chromatograms for chromatographic paper and GO-modified paper, both applied to PSI-MS creatinine in urine samples analysis.

\section{Quantification of creatinine in urine}

The linearity of the GO-PSI/MS method for creatinine determination in urine samples was assessed by the analytical curve (Figure S3, SI section). The analytical curve was constructed using the absolute intensity of the fragment ion, $m / z 86$, as a function of concentration. The method showed linearity between 0.1 to $3.4 \mathrm{ppm}$ with $\mathrm{R}^{2}=0.9991$. The LOQ and LOD were determined based on S/N higher than 10 and 3, respectively. According to the obtained results the LOQ was $0.17 \mathrm{ppm}$ and LOD $0.05 \mathrm{ppm}$.

The developed GO-PSI-MS method was compared with the chromatographic paper, in three concentrations levels (0.1, 1.4 and $3.4 \mathrm{ppm})$. These obtained values are shown in Table 1. The GO-PSI-MS developed method presented accuracy over $96.8 \%$ in the range of all analyzed concentrations. The interday precision was presented by the

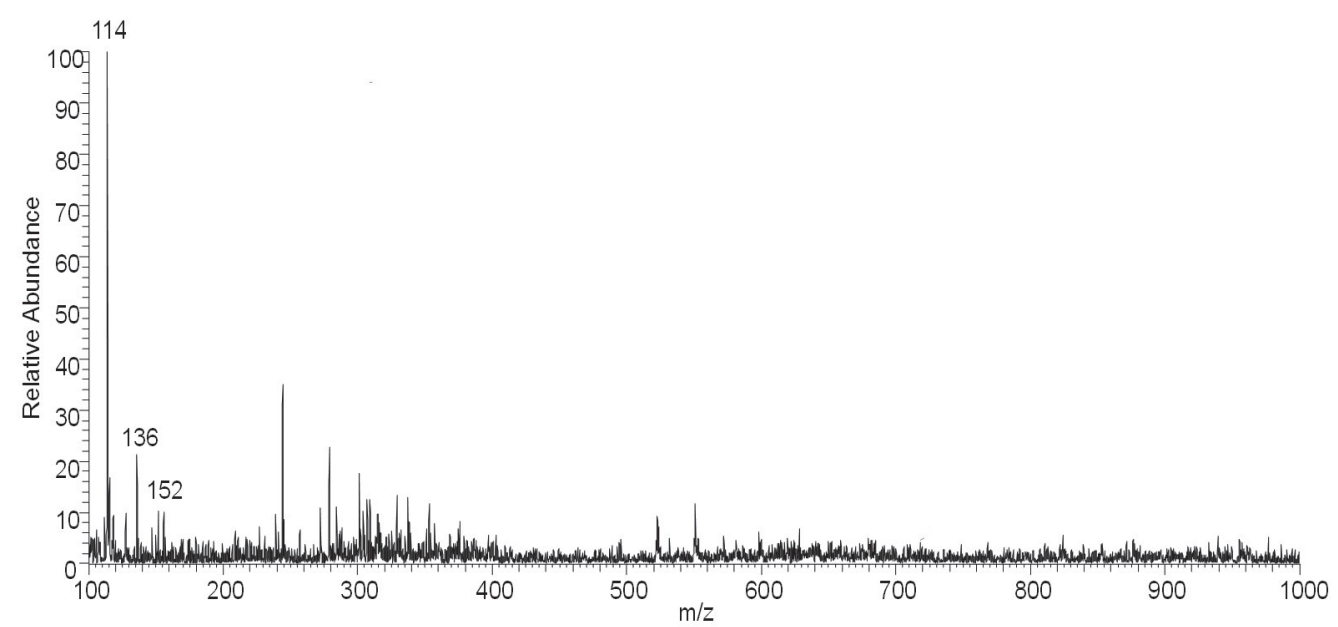

Figure 5. PSI(+)-MS of creatinine in urine real samples, $\mathrm{m} / \mathrm{z}$ from 100 to 1000. 
Table 1. Interday precision, accuracy and absolute recovery of the PSI-MS method for creatinine using modified and chromatographic papers

\begin{tabular}{lcccc}
\hline PSI substrate & Concentration / ppm & Precision CV / $\%$ & Accuracy / \% & Absolute recovery / \% \\
\hline \multirow{3}{*}{ GO-modified paper } & 0.1 & 6.8 & 4.5 & 96.8 \\
& 1.4 & 4.2 & 1.3 & 99.5 \\
\hline \multirow{2}{*}{ Chromatographic paper } & 3.4 & 1.1 & 0.1 & 100.9 \\
& 1.0 & 9.6 & 8.8 & 102.4 \\
& 1.4 & 9.2 & 8.9 & 96.4 \\
\hline
\end{tabular}

${ }^{a}$ Coefficient of variation. PSI: paper spray ionization; GO: graphene oxide.

coefficient of variation (CV) and the values were lower than $6.8 \%$. For unmodified chromatographic paper, the results were acceptable only at concentrations greater than $1.0 \mathrm{ppm}$ with accuracy of $102.4 \%$.

Kwon et al. ${ }^{47}$ developed a method for the analysis of creatinine in urine using liquid chromatography-tandem mass spectrometry (LC-MS), obtaining values of LOQ and LOD of 10 and 3 ppm, respectively, while the method developed here presented LOQ of $0.17 \mathrm{ppm}$ and LOD of $0.05 \mathrm{ppm}$, with precision and accuracy. In addition, there is the fact that the PSI-MS technique is a faster analysis with almost no solvent consumption when compared to the LC-MS technique that demands a considerable time of chromatographic run. ${ }^{47}$

\section{Real urine samples}

To evaluate the proposed method for clinical use, the described protocol was applied to the analysis of urine samples of healthy volunteers. Twenty-four samples were analyzed, and the creatinine concentrations found in these samples ranged from 0.9 to $3.6 \mathrm{ppm}$.

The PSI-GO-MS developed method for creatinine in urine samples analysis was shown to be a potential tool for clinical determination, exhibiting great accuracy and specificity when compared to conventional methods for creatinine determination.

\section{Conclusions}

In this study, graphene oxide was synthesized and immobilized onto cellulose paper surface, and afterward the developed substrate was used in PSI-MS method for creatinine determination in urine samples.

The GO-PSI-MS developed method is based on simple ionization, besides being an easy to perform, fast, and powerful outdoors technique that can be used for highperformance analysis. The technique does not require sheath gas, heating or materials for analysis of samples and sample preparation for complex samples, such as urine, and does not suffer from interferences compared to the traditional methods for creatinine analysis. GO considerably improves spray stability and results in the lower LOQ when compared to chromatographic paper (conventional substrate).

The developed method showed adequate accuracy (lower than 4.5\%), precision (lower than 6.8\%) and LOQ $(0.1 \mathrm{ppm})$ values. Real urine samples were subjected to GO-PSI-MS analysis to creatinine biomonitoring levels, and the results showed the adequate performance of the developed method for clinical purposes.

\section{Supplementary Information}

Supplementary data (total ion chromatograms, GO-PSIMS/MS spectrum and analytical curve) are avaiable free of charge at http://jbcs.sbq.org.br as a PDF file.

\section{Acknowledgments}

This work was supported by grants from Conselho Nacional de Desenvolvimento Científico e Tecnológico (CNPq 447927/2014-0). The authors thank the Grupo de Métodos Eletroforéticos (GME), Universidade Federal de Goiás, for donating creatinine standard solution.

\section{References}

1. Wang, H.; Liu, J.; Cooks, R. G.; Ouyang, Z.; Angew. Chem. 2010, 122, 889.

2. Espy, R. D.; Manicke, N. E.; Ouyang, Z.; Cooks, R. G.; Analyst 2012, 137, 2344.

3. Lin, C. H.; Liao, W. C.; Chen, H. K.; Kuo, T.; Bioanalysis 2014, 2, 199.

4. Hamid, A. M.; Jarmusch, A. K.; Pirro, V.; Pincus, D. H.; Clay, B. G.; Gervasi, G.; Cooks, R. G.; Anal. Chem. 2014, 86, 7500.

5. Espy, R. D.; Teunissen, S. F.; Manicke, N. E.; Ren, Y.; Ouyang, Z.; Van, A. A.; Cooks, R. G.; Anal. Chem. 2014, 86, 7712. 
6. Zhang, C., Manicke, N. E.; Anal. Chem. 2015, 87, 6212.

7. Liu, W.; Wang, N.; Lin, X.; Ma, Y.; Lin, J. M.; Anal. Chem. 2014, 87, 7128.

8. Jjunju, F. P. M.; Maher, S.; Damon, D. E.; Barrett, R. M.; Syed, S. U.; Heeren, R. M. A.; Taylor, S.; Badutawiah, A. K.; Anal. Chem. 2016, 88, 1391.

9. Deng, J. W.; Yang, Y. Y.; Anal. Chim. Acta 2013, 785, 82.

10. Su, Y.; Wang, H.; Liu, J. J.; Wei, P.; Cooks, R. G.; Ouyang, Z.; Analyst 2013, 138, 4443.

11. Li, A.; Wei, P.; Hsu, H. C.; Cooks, R. G.; Analyst 2013, 138, 4624.

12. Liu, J. J.; Gu, Z. X.; Yao, S. Z.; Zhang, Z. H.; Bo, C.; J. Pharm. Biomed. Anal. 2016, 124, 93.

13. Tepper, G.; Kessick, R.; Appl. Phys. Lett. 2009, 94, 084196.

14. Hu, B.; So, P. K.; Chen, H.; Yao, Z. P; Anal. Chem. 2011, 83, 8201.

15. Maa, Q.; Bai, H.; Li, W.; Wang, C.; Cooks, R. G.; Ouyang, Z.; Talanta 2015, 142, 190.

16. Manicke, N. E.; Yang, Q.; Wang, H.; Oradu, S.; Ouyang, Z.; Cooks, R. G.; Int. J. Mass Spectrom. 2011, 300, 123.

17. Wang, H.; Manicke, N. E.; Yang, Q.; Shi, L. R.; Cooks, R. G.; Ouyang, Z.; Anal. Chem. 2011, 83, 1197.

18. Zhang, Z.; Cooks, R. G.; Ouyang, Z.; Analyst 2012, 137, 2556.

19. Gao, Y.; Qin, C.; Qiao, Z.; Wang, B.; Li, W.; Zhang, G.; Chen, R.; Xiao, L.; Jia, S.; Carbon 2015, 93, 843.

20. Dreyer, D. R.; Todd, A. D.; Bielawski, C. W.; Chem. Soc. Rev. 2014, 43, 5288.

21. Upadhyay, R. K.; Soin, N.; Bhattacharya, G.; Saha, S.; Barman, A.; Roy, S. S.; Mater. Lett. 2015, 160, 355.

22. Krishnamoorthy, K.; Ramadoss, A.; Kim, S. J.; Sci. Adv. Mater. 2013, 5, 406.

23. Park, J. H.; Park, J. M.; Surf. Coat. Technol. 2014, 254, 167.

24. Hu, X. B.; Yu, Y.; Hou, W. M.; Zhou, J. E.; Song, L.; Appl. Surf. Sci. 2013, 273, 118.

25. Rasuli, R.; Mokarian, Z.; Karimi, R.; Shabanzadeh, H.; Abedini, Y.; Thin Solid Films 2015, 589, 364.

26. Hu, X. B.; Yu, Y.; Zhou, J. E.; Song, L.; Nano 2014, 9, 1450037.

27. Zanin, H.; Saito, E.; Ceragioli, H. J.; Baranauskas, V.; Corat, E. J.; Mater. Res. Bull. 2014, 49, 487.
28. Kou, L.; Gao, C.; Nanoscale 2011, 3, 519.

29. Wei, S. C.; Fan, S.; Lien, C. W.; Unnikrishnan, B.; Wang, Y. S.; Chu, H. W.; Huang, C. C.; Hsu, P. H.; Chang, H. T.; Anal. Chim. Acta 2018, 1003, 42.

30. Zanin, H.; Saito, E.; Marciano, F. R.; Ceragioli, H. J.; Granato, A. E. C.; Porcionatto, M.; J. Mater. Chem. B 2013, 1, 4947.

31. Araújo, W. R.; Salles, M. O.; Paixão, T. R. L. C.; Sens. Actuators, B 2012, 173, 847.

32. Koncki, R.; TrAC, Trends Anal. Chem. 2008, 27, 304.

33. Bhagavan. N. V.; Medical Biochemistry, $4^{\text {th }}$ ed.; Harcourt Academic Press: Orlando, 2002.

34. Myers, G. L.; Miller, W. G.; Coresh, J.; Fleming, J.; Greenberg, N.; Greene, T.; Clin. Chem. 2006, 52, 5.

35. Randviir, E. P.; Banks, C. E.; Sens. Actuators, B 2013, 183, 239.

36. Dbira, S.; Cañizares, P.; Rodrigo, M. A.; J. Electroanal. Chem. 2015, 744, 62 .

37. Mendes, T. P. P.; Pereira, I.; Ferreira, M. R.; Chaves, A. R.; Vaz, B. G.; Anal. Methods 2017, 9, 6117.

38. Zargar, T.; Khayamian, T.; Jafori, M. T.; J. Pharm. Biomed. Anal. 2017, 132, 232.

39. Zheng, Y.; Wang, Q.; Wang, X.; Chen, Y.; Wang, X.; Zhang, X.; Bai, Z.; Han, X.; Zhang, Z.; Anal. Chem. 2016, 88, 7005.

40. Chen, J.; Hu, Y.; Shi, M.; Lu, X.; Qin, C.; Li, C.; Ye, M.; Chem. Mater. 2009, 21, 3514

41. Annesley, T. M.; Clin. Chem. 2003, 49, 1041.

42. Fujii, T.; Mass Spectrom. Rev. 2000, 19, 111.

43. Furey, A.; Moriarty, M.; Bane, V.; Kinsella, B.; Lehane, M.; Talanta 2013, 115, 104.

44. Liu, A. C.; Lin, T. Y.; Su, L. W.; Fuh, M. R.; Talanta 2008, 75, 198.

45. Antignac, J. P.; Wasch, K.; Monteau, F.; De Brabander, H.; Andre, F.; Le Bizec, B.; Anal. Chim. Acta 2005, 529, 129.

46. Nicolardi, S.; van der Burgt, Y. E. M.; Codée, J. D. C.; Wuhrer, M.; Hokke, C. H.; Chiodo, F.; ACS Nano 2017, 11, 8257.

47. Kwon, W.; Kim, J. Y.; Suh, S.; Kyo, M.; Forensic Sci. Int. 2012, 221, 57.

Submitted: August 27, 2018

Published online: January 11, 2019 